\title{
MIMESES DO SUBLIME: A RECEPÇÃO DE KANT PELO ROMANTISMO E PELO EXPRESSIONISMO
}

\author{
Priscila Rossinetti RUFINONI ${ }^{1}$
}

- RESUMO: Partindo das analises do criticismo kantiano, este texto investiga as concepções romântica e moderna de sublime e de imaginação. Se, por um lado, a concepção romântica inaugura o mundo moderno, por outro, a expressionista mostra os limites dessa mesma modernidade. Para ambas, entretanto, a Crítica do Juízo de Kant é o âmbito privilegiado no qual podemos precisar as distinções.

- PALAVRAS-CHAVE: sublime, Kant, romantismo, expressionismo, mimese.

Já é lugar-comum reconhecer que Kant não se interessava pelas "Belas-Artes" propriamente, e, portanto, não escreveu qualquer "Estética" no sentido em que essa palavra passou a ser utilizada a partir do século XVIII. Assim, pode parecer uma ponte pouco firme a que sustenta a passagem da teoria à prática, da estética pura à filosofia da arte e desta, sorrateiramente, para a objetividade da história da arte. Talvez isso não aconteça se pensarmos que os termos da discussão "estética" de Kant - belo, sublime e suas variantes gradativas grotesco, pitoresco, belo natural, gracioso - eram moeda comum nos debates sobre arte e nos comércios artísticos do século XVII. Giovanni Pietro Bellori e Nicolas Poussin tematizavam o "não sei o quê" capaz de fazer a passagem entre imagem sensível e idéia inteligível. Para Poussin: "A forma de uma coisa se distingue por sua própria operação ou fim: algumas operam o riso, o terror e tais são suas formas" (Poussin, 1964, p.174). Outro pintor, Anton Raphael Mengs, por volta dos anos de 1770, escreve que "por estilo sublime entendo aquele modo de tratar a Arte

1 Doutoranda no Programa de Pós-Graduação em Filosofia da Universidade de São Paulo (Usp) sob orientação de Leon Kossovitch. Artigo recebido em dez/06 e aprovado em jun/07. 
que convém à execução de idéias com as quais se quer fazer conceber a quem mira a pintura, objetos de qualidades superiores a nossa natureza" (apud Bozal, 1994). Estes termos "estéticos" reaparecerão constantemente nas filosofias modernas, de Kant a Nietzsche. Em 1888, Nietzsche, para reafirmar sua crítica ao pathos romântico fundado na sensibilidade ao detalhe dramático, ao rugoso, escreve: "o pathos das atitudes não pertence à grandeza; quem em geral necessita de atitude é falso... Cuidado com os homens pitorescos" (Nietzsche, 1974, p.373). Palavra já em circulação no século XVII, "pitoresco", ou pínturesco, designa as vistas rurais, as ruínas que dão uma nota de interesse e grandeza às paisagens depois chamadas "românticas". As mesmas ruínas, em outra gradação hierárquica, reaparecem como metáforas do espetáculo "sublime" da Revolução Francesa, reatualização da Antigüidade em uma arqueologia política e visual. Desse sublime ético são exemplos as pinturas de Jacques-Louis David.

O caminho de volta - da filosofia à arte - é ainda mais difícil, se pensarmos que o artista não é um pensador, que não há uma disposição filosófica anterior à obra. Mas a reelaboração dos termos da "estética" empreendida por Kant é uma espécie de "condição de possibilidade" para a arte moderna, notadamente em sua vertente romântica e, depois, expressionista: uma outra revolução copernicana. Kant cria o sistema mais acabado para se pensar o homem em relação a essa natureza pictórica adequada ao gosto humano, nas várias gradações hierárquicas legadas pelo século XVII. A sua obra dá estatuto filosófico ao homem que julga, ao observador distanciado, esse prenúncio iluminista do que será o cientista do século XIX. O homem-cientista, o homem moderno, será sujeito em relação ao objeto, ponto marcante das teorias românticas que Nietzsche irá desmascarar como a maior das ilusões antropomórficas em vários de seus aforismos. Aquele mesmo homem-observador que o pintor Caspar Friedrich figura em suas paisagens.

Se compararmos uma pintura romântica, Vilarejo junto ao mar de neblina, (1888), de Caspar David Friedrich, a uma obra já ligada ao Expressionismo, a gravura Fábrica (1930) de Oswaldo Goeldi, ${ }^{2}$ perceberemos ao mesmo tempo a proximidade e a distância entre as visões romântica e expressionista. O ponto de vista de Friedrich, marcado pela personagem recortada contra o fundo, é externo, de um contemplador privilegiado da natureza. $\mathrm{Na}$ gravura de Goeldi, os planos murados quebram a visão e destacam a verticalidade fantasmagórica das grandes chaminés algo arruinadas, umas justapostas às outras, em uma espacialidade opressiva. O aspecto de ruínas, a desproporção das chaminés são apresentações da cidade-monstro, da cida-

2 Caspar David Friedrich, Vilarejo sobre o mar de neblina, óleo sobre tela, Hamburgo, Kunsthalle; Oswaldo Goeldi, Fábrica, xilogravura, Rio de Janeiro, Museu Nacional de Belas Artes. Cf. Jensen, 1980; Rufinoni, 2000. 
de Molock do Expressionismo. A monumentalização disforme e "naturalizante" das construções; o hálito sombrio que impregna o céu de "nuvens", de "tempestades" de fumaça; ou mesmo a desproporção entre o homem e o plano agigantado das chaminés metamorfoseiam a cidade em natureza sublime. A notação de ruínas com que Goeldi descreve o muro, as chaminés, também se inscreve na velha tópica de evocar o sublime pela alusão fatalista da passagem do tempo, deslocando-a para o contexto da metrópole.

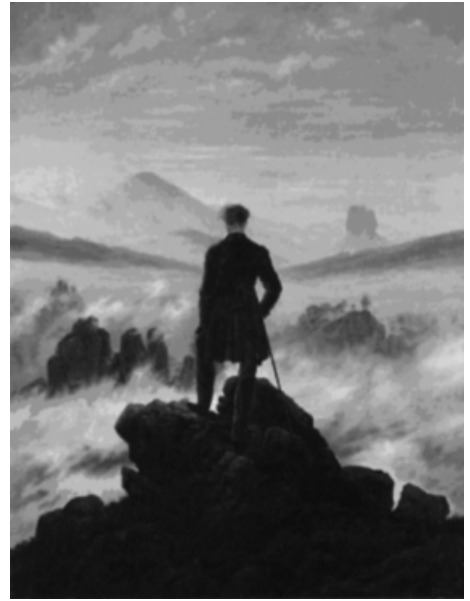

FIGURA 1 - Caspar David Friedrich, Vilarejo sobre o mar de neblina, óleo sobre tela, Hamburgo, Kunsthalle.

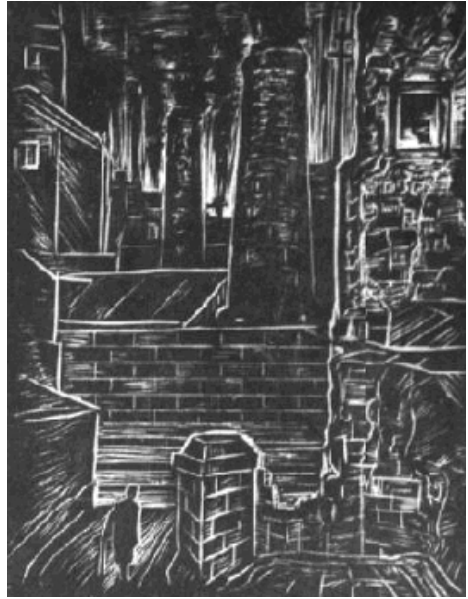

FIGURA 2 - Oswaldo Goeldi, [Fábrica], xilogravura, Rio de Janeiro, Museu Nacional de Belas Artes.

Nesse nível iconográfico o conceito de sublime, como foi definido em seus termos modernos no tratado de Burke, Uma Investigação Filosófica sobre a origem de nossas idéias do sublime e do belo, mantém apenas características antropológicas, relativas a uma psicologia do gosto. Ou seja, uma ruína, em seu aspecto rugoso, em seu poder de despertar analogias com idéias de destruição e perigo, não é bela aos sentidos, não é agradável ao entendimento, despertando uma forma de prazer diversa; o sublime é este sentimento criado pela associação dolorosa de imagens e formas desagradáveis, à primeira vista, aos sentidos e ao entendimento, mas que se transformam também em deleite. ${ }^{3}$ Mas, se procuramos compreender para além

3 "Porém, se o sublime se funda no terror ou em alguma paixão análoga que tenha como objeto a dor, convém investigar, antes de mais nada, como algum tipo de deleite pode advir de uma causa tão oposta a ele. Digo deleite porque, como afirmei repetidas vezes, sua causa assim como sua própria natureza são claramente diferentes das do prazer positivo e real" (Burke, 1993, p.140). 
da iconografia a retomada de pressupostos românticos pelo Expressionismo, a matriz primeira da teoria do Romantismo deve ser a Crítica do Juízo de Kant. Nesse texto o autor, embora ainda bastante influenciado por Burke, desloca os sentimentos estéticos da esfera do gosto para fazê-los adentrar a arquitetura geral da razão humana.

Será preciso fazer uma breve apresentação das questões da Crítica do Juízo; exposição que, se não se pretende original, procurará, no didatismo, pontuar outras ênfases. A natureza que Kant propõe na terceira crítica precisa ser "adequada" à razão humana - para aproximar sem contradições liberdade e natureza - superando a tendência mecanicista do sistema. A "natureza", do ponto de vista da Crítica do Juízo, difere daquela explicitada pelas categorias da razão pura, daquela natureza esquemática da primeira crítica, pois, divergindo dos juízos do entendimento que determinam - são determinantes -, os juízos estéticos apenas refletem subjetivamente - são reflexionantes. ${ }^{4}$ Para resolver o problema de um princípio a priori para a faculdade do juízo, sem subsumi-la à determinação, Kant amplia a auto-gestão do sujeito transcendental: o juízo dá a si mesmo um conjunto de leis a priori que lhe permite pensar a natureza de diversos modos, na forma reflexiva e sem conceitos das aproximações estéticas ou teleológicas, na forma condicional do "como se". Assim, o juízo humano procede a uma especificação que não é mecanicista. A natureza é dotada de um projeto, um "sentido", pois, pelo menos para os juízos reflexionantes, ela é pensada como se fosse engenhosamente concebida, como "arte".

Esse sentimento técnico no qual se unem imaginação e razão é o que Kant chama de belo. No sentimento do sublime kantiano, a imaginação concorre com a razão, provocando uma espécie de cacofonia. Se o sentimento do belo, pela concordância harmônica de duas faculdades, cria familiaridade e prazer, o sublime é o estranho, o incontrolável, uma grandeza absoluta que abisma a imaginação em uma inação, uma impotência. Mas ainda assim, mesmo que imaginação e razão não estejam em acordo, "as antinomias coagem a contragosto o olhar para além do sensível e a procurar no suprasensível o ponto de convergência de todas as faculdades a priori; pois não resta outra saída para fazer a razão concordar consigo mesma" (Kant, 1992,

4 Já na Primeira Introdução à Crítica do Juízo, Kant tenta deixar claro qual o lugar da terceira crítica na arquitetura sistêmica de seu projeto: "ora, a faculdade-de-conhecimento segundo conceitos tem seus princípios a priori no entendimento puro (em seu conceito de natureza), a faculdade-dedesejar, na razão pura (em seu conceito de liberdade), e assim resta ainda entre as propriedades da mente em geral uma faculdade ou receptividade média, ou seja, o sentimento de prazer e desprazer, assim como entre as faculdades superiores do conhecimento, uma faculdade média, o Juízo. O que é mais natural do que supor; que esta última conterá igualmente princípios a priori para a primeira" (Kant, 1980, p.174). 
p.249). Se no sentimento do belo é pelo jogo entre entendimento e imaginação que a antinomia se resolve, permitindo que a natureza exterior seja adequada ao homem; no sublime a experiência de uma exterioridade informe, da heterogeneidade irredutível a conceitos, causa desprazer e não pode ser apreendida ludicamente como "bela". No ponto extremo em que a grandeza natural, a angústia de sua violência, abisma a intuição da imaginação - o sensível -, a razão ainda pode dar sentido ao caos natural, um sentido superior, cuja consonância não é meramente formal como a que se estabelece entre imaginação e entendimento, mas aciona as leis racionais.

Ambos os juízos estéticos, belo e sublime, são abertos, reflexionantes. Mais interessante para a teoria estética é uma segunda conseqüência atrelada a esta autojurisdição dos juízos reflexivos estéticos, inferência mais do Romantismo que do próprio Kant: temos dada a possibilidade de uma estética absolutamente não preceptiva. Uma estética normativa pode ser refutada pela idéia de que é apenas no jogo subjetivo das faculdades promovido pelo juízo, ao dar leis a si próprio, que temos o juízo estético. É no trabalho do gênio, sujeito no qual a natureza pode articular sua mecanicidade à liberdade humana (causalidade eficiente e final), que estão dadas as regras da arte, também subjetivamente. O gênio é, assim, não subjetividade individualista, mas orgânico, "vegetal", já que pressupõe uma predisposição da natureza. A arte não é um produto que podemos criar (ou reconhecer) a partir de regras pré-estabelecidas, portanto não é mimese de um belo anterior. Não há mais gêneros perfeitos aos quais as poesias (e as pinturas) se aproximam de forma mais ou menos acabada, não há nem mimese "tirada do natural", naquela eleição exemplar de Zêuxis ao escolher as partes mais belas das jovens para a sua mais bela mulher, ${ }^{5}$ nem mimese de um gênero canônico; não há mais simbologia absoluta. Como diz Schelling em relação à poesia de Dante, a modernidade tem por regra apenas a originalidade, não a exemplaridade; se a Divina Comédia é exemplar, o é por sua absoluta originalidade que, ao fundar um "gênero por si", o esgota (Schelling, 1991, p.58-68).

Outra decorrência da terceira crítica, a que talvez possamos creditar grande parte da filosofia romântica, é o novo lugar ocupado pela imaginação: ela não é um esquema que representa o particular para que o entendimento o subsuma a um conceito determinante e universal, mas uma faculdade em jogo com os conceitos indeterminados ou com as idéias morais; uma faculdade que pode dar a estas operações da razão um plano de exposição simbólica. Se as idéias da liberdade humana não podem ser objetiva-

5 A figura de Zêuxis, cuja citação remonta ao texto de Plínio, reaparece citada por Alberti em Da Pintura e, depois, é evocada pelos defensores de Poussin, constituindo a tradição de mimese como eleição do natural (cf. Alberti, 1992, p.133). 
mente expostas em conceitos, elas podem sê-lo subjetivamente, isto é, pelas idéias estéticas criadas pelos juízos reflexionantes. Assim, o gênio pode, criando uma espécie de acordo entre imaginação/entendimento, imaginação/razão, dar-nos expostos em um símbolo os conteúdos morais da razão. Para Kant a aproximação de idéias do ato de simbolizar, espécie de analogia interna entre conceitos e intuições, não opera por semelhança, mas pelas "regras de refletir sobre ambos e sua causalidade" (Kant, 1992, p.261). São "apresentações indiretas", nas palavras de Kant. Mais que símbolos, se pensarmos nas figuras da linguagem retórica, são metáforas que criam, por afinidades eletivas, demonstrações subjetivas. Seriam então um "andaime analógico", como diz Jean-François Lyotard nas suas Lições sobre a Analítica do Sublime, ensaiando a ponte possível entre sensibilidade e razão? (cf. Lyotard, 1993, p.157; a expressão "cacofonia" devemos a Lyotard). Aquela mesma ponte perfeita entre imagem e idéia a que aspirava Nicolas Poussin?

Essa "ponte possível", esse senso comunis dos homens que julgam, será a arena comunitária que permitirá tanto a "educação estética" romântica quanto a ruptura expressionista com os códigos de representação. Apesar de fundamentado na busca da totalidade, de um Absoluto - vislumbrado na imediatez do símbolo, ou na mitologia antiga -, os pressupostos de uma racionalidade estética que o romantismo anuncia podem fazer uma ponte entre o sujeito solipsista monológico e um contexto intersubjetivo. Relação de "comunicabilidade" ainda mais interessante se pensarmos que a "educação estética", depois dos juízos kantianos, se dá como procedimento das faculdades em livre jogo e não por um conteúdo dogmático "alegórico" constituído por exemplos externos. Hannah Arendt chama a atenção para o § 40 da Crítica do Juízo de Kant: são juízos estéticos as bases de um senso comunis, pois são juízos "desinteressados" e finalidades sem fins, próprios a uma arena pública em que os homens que julgam a história precisam viver em "comunicabilidade", não apenas segundo normas mecanicistas. ${ }^{6}$ Senso comunis não é, portanto, um senso comum, uma deliberação imediata acerca de algo, uma deliberação objetiva, mas senso comunitário.? Além do contrato inteligível e metafísico no supra-sensível de que todo ho-

6 "Por senso comunis, porém, tem que se entender a idéia de um sentido comunitário (gemeinschaftlichen) isto é, de uma faculdade de julgamento, que na sua reflexão considera em pensamento (a priori) o modo de representar de todo o outro, como que para ater seu juízo à inteira razão humana e assim escapar à ilusão que - a partir de condições privadas subjetivas, as quais facilmente poderiam ser tomadas por objetivas - teria influência prejudicial sobre o juízo" (Kant, 1992, $\S 40$, p.196. Cf. Arendt, 1993).

7 Segundo Habermas, Schiller mistura "tacitamente o conceito kantiano de juízo com o conceito tradicional, que na linha aristotélica (chegando até mesmo a Hannah Arendt) nunca perdera o vínculo com o conceito político de senso comunitário" (Habermas, 2000, p.69). 
mem racional participa, Kant pensa em um contrato de "comunicabilidade" universal entre os homens que julgam reflexivamente a história e a natureza. Se, pelos julgamentos da Crítica da Razão Pura, a natureza e a história são mecanicistas e os juízos determinantes, quando Kant amplia a razão com a Crítica do Juízo, a racionalidade pode também julgar segundo um sistema finalista, como se a natureza e a história fossem "técnica", "arte". Neste sentido Schiller pensa a "maior de todas as obras de arte" como sendo a "construção de uma verdadeira liberdade política" (Schiller, 1989, p.25; cf. também Habermas, 2000, p.66).

A ruptura com a representação, com os gêneros canônicos, já não precisa ser uma cisão com qualquer sentimento comum de humanidade. A imaginação, antes faculdade do erro, do impreciso, torna-se o lugar privilegiado para a compreensão da liberdade humana. Mesmo quando o gênio romântico reivindica sua total autonomia, é em sua imaginação aberta ao indeterminado que se congraçam causalidade eficiente e final, natureza e liberdade. Pensamento que permite o aparente paradoxo de a ruptura com a representação dos expressionistas e as concepções da "arte pela arte" buscarem ser ao mesmo tempo perscrutadoras de conteúdos ocultos, morais. Tanto quanto as figuras, o arabesco livre dos desenhos, a pincelada das pinturas, pressupõem a faculdade da imaginação como o caminho para a expressão dos conflitos do homem. O artista seria, então, não o artífice de uma forma pré-concebida exemplar, mas um "fino instrumento do infinito". 8 Ou, em outra formulação mais conhecida, o artista passa a ter uma função política privilegiada, a de "antena da raça".

Como a harmonia proporcionada pelos juízos do belo cada vez mais deixa de ser capaz de dar conta das cisões modernas, a imaginação romântica procura seus limites. Mesmo quando incapaz de abarcar a totalidade diante do "sublime", a imaginação, na figura do artista, é chamada a representar o Absoluto. ${ }^{9}$ Em Kant, mais que um subterfúgio psicológico para causar-nos assombro (e deleite) ante um perigo ou dor fictícios, o sublime é uma consonância das faculdades que entendem a natureza, mesmo quando esta não pode dar-se em uma intuição, como em conformidade a fins, como sentido. Se a violência natural, para Kant, não pode ser abarcada pela sensibilidade, ainda há como dar conta deste assombro: mesmo que a imaginação se abisme em um desprazer, esta visão mobiliza, por outro lado, a razão humana e

8 Carta do desenhista austríaco Alfred Kubin a Oswaldo Goeldi, Reproduzida em Oswaldo Goeldi, Rio de Janeiro: PUC, 1982, não paginado.

9 "o que se experimenta no sublime não é a boa proporção no jogo das duas faculdades que aí estão em exercício, mas sua desproporção e até sua incomensurabilidade: um 'abismo, Abgrund' separa-os, que 'assusta' e 'atrai' a imaginação chamada a representar o absoluto" (Lyotard, 1993, p.29). 
dá uma conformidade a fins, uma finalidade, ao informe natural, e um prazer nesta adequação da natureza às leis racionais. Para Adorno este processo opera o deslocamento da angústia humana perante o exterior indomado para uma angústia moral: "em Kant, a angústia perante a violência natural começou a tornar-se anacrônica através da consciência da liberdade do sujeito; esta foi repelida pela sua angústia perante a servidão perpétua. Ambas as formas de angústia se contraem na experiência do belo natural" (Adorno, s.d., p.81). O sujeito que experimenta o mundo não é mais assombrado por este, livro enigmático a escapar da razão pelas frestas do acaso, mas as angústias são internalizadas. Ou, dito de outra maneira, a modernidade opera uma imersão: "A alegoria barroca vê o cadáver apenas de fora, Baudelaire o vê também de dentro" (Benjamin, 1991, p.175). É como se a modernidade, apoiada no kantismo, ao operar a cisão entre sujeito e objeto, operasse também a internalização dos conflitos. Da relação entre homem e natureza, para uma comunhão muitas vezes angustiante do homem no mundo; da natureza exterior para a visão das cidades como segunda natureza. Essa angústia reivindica o sublime como mimese original do que não pode ser catalogado em gêneros, do que é sempre cindido, sempre incompleto.

O conceito de sublime, entretanto, já sofreu acomodações, desdobramentos e ressignificações. Séculos depois de consolidada uma natureza segunda para o homem - as cidades -, Adorno refaz a questão do homem e do natural: "o caráter errôneo da antítese vulgar de técnica e natureza reside manifestamente no fato de a natureza não-contaminada pela intervenção humana (...), as morenas e as ladeiras de seixos soltos alpinas se assemelharem às montanhas de dejetos industriais" (Adorno, s.d., p.84). A cidade moderna, segunda natureza petrificada, tão violenta e informe quanto sua falsa antítese - o natural -, também mobiliza outras formas de apreensão além do sensível: o sublime como último limite da racionalidade, mesmo que em negativo.Mas é claro que, da perspectiva de Adorno, essa razão que enquadra - pelo positivo ou pelo negativo, pelo belo ou pelo sublime - a natureza ou as imagens não é mais aquela ratio iluminista a que Hannah Arendt ainda faz menção. A razão kantiana formalizada em juízos, para a modernidade só pode ser um mecanismo de racionalização; esta a razão "se tornou a finalidade sem fim que, por isso mesmo, se deixa atrelar a todos os fins" (Adorno \& Horkheimer, 1985, p.87). O Expressionismo, desta visada, seria um gesto, um "esquema de atividade" descolado de seu conteúdo.

Voltando ao nível iconográfico, fica evidente que é a cidade, e não o mar infinito ou a incomensurabilidade das montanhas, a personagem apocalíptica do Expressionismo. Lugar da caducidade do indivíduo, cenário das revoluções, dos acontecimentos históricos, é o mundo urbano que faz o expressionista figurar, antagonicamente, o campo idílico. Resumindo muitas visões expressionistas da grande cidade, do monstro capitalista, temos 
o filme Metrópolis, de 1926. Anteriormente era o mundo natural o espaço do que não tínhamos como apreender formalmente. Em contraste às construções técnicas humanas, este era o lugar do caos informe, do sublime. Com a consolidação para o mundo moderno de uma segunda natureza tecnológica na face das metrópoles, esta oposição tornou-se falsa. Há um mimetismo entre o resíduo das sociedades urbanas e a desorganização natural que os expressionistas não deixaram de compreender (Adorno, s.d., p.84). Não é à toa que Adorno reconhece uma reificação na hybris expressionista em querer escapar da representação por meio do gesto, como se verá. A natureza expressionista é apenas nostálgica, seu ambiente é o mundo das coisas. Nesta passagem do natural para as "coisas", o homem deixa de ser apenas sujeito desinteressado, para ser ao mesmo tempo observador e artífice ${ }^{10} \mathrm{E}$ a modernidade põe um outro problema, o desse sublime que é, de alguma forma, mimético, pois é artefato, arte, e não apenas julgado como tal, "como se", pois é concebido para despertar sentimentos no espectador, porquanto poético, figura tão estranha à Crítica de Kant quanto aquela imaginação reformulada pelos românticos.

Se o sublime é o que não podemos apreender pela forma, pela sensibilidade, para as artes visuais, artes da aparência, evocá-lo seria impossível. Esta é a perspectiva tradicional, adotada por Burke: o artista, quando busca na pintura a sublimidade, só logra atingir formalizações ridículas, disformes, grotescas. Apesar de os artistas anteriores à modernidade enfrentarem esse limite, seja pela representação da paisagem, seja pela alegoria, a reinterpretação do conceito para além do nível iconográfico é marca da ruptura moderna. Marca de uma constante tensão entre a aparência e a espiritualidade, potencializada pelas obras que buscam romper o caráter espetacular do objeto artístico em função de sua pura espiritualização. Essa tensão reivindica o sublime kantiano como conceito constituinte das novas poéticas. Se pensarmos que o espiritual em uma obra é o "não-representável sensível", veremos que a doutrina de Kant descreve "com maior razão uma arte que estremece em si, ao suspender-se em nome de um conteúdo de verdade evidente sem, no entanto, enquanto arte, perder seu caráter de aparência". Ou seja, "as obras em que a estrutura estética se transcende sob pressão do conteúdo de verdade ocupam um lugar que outrora indicava o conceito de sublime" (Adorno, s.d., p.222). Deslocado do âmbito de nosso sentimento em relação à natureza, já que Adorno reconhece que é nas obras artísticas que pode dar-se esse embate homem/belo natural, ${ }^{11}$ o sublime

10 Duplo papel que também pode corroborar a transformação da razão iluminista em racionalização, em "esquemas de ação".

11 "A teoria kantiana do sublime antecipa na natureza aquela espiritualização que só a arte realiza" (Adorno, s.d., p.111). 
passa a ocupar um espaço central na recepção da arte moderna: "o sublime, que Kant reservava à natureza, tornou-se depois dele constituinte histórico da própria arte. O sublime traça a linha de demarcação em relação ao que mais tarde se chamou artesanato" (ibidem). Para a modernidade o sublime é o limite entre a "arte" e a sua "mecânica".

Grosso modo, o Expressionismo abdica da representação, da mimese clássica, em busca de uma "verdade" anterior dada no próprio ato de criar. Por isso, as pinceladas ficam aparentes, o gesto evidenciado; por isso o uso da xilogravura, técnica rústica, pouco afeita às delicadezas da verossimilhança. Para usar termos kantianos, a "mecânica" da arte desnuda, nos objetos, sua característica de "bela arte", de arte refletida e não apenas material. O perigo, suspeitado por Kant e enunciado claramente por Adorno, é uma nova cisão, a "desmaterialização" do objeto arte, da mediação "obra" no puro jogo de sujeitos "geniais". Kant reconhece essa tendência meramente "lúdica" na arte de seu tempo. ${ }^{12}$ Da perspectiva supra-sensível que o sublime concede às obras, Adorno sintetiza esses mesmos antagonismos na arte expressionista: "também correntes anti-realistas como o expressionismo participam da rebelião contra a aparência. Ao ele opor-se à cópia do exterior, tendia para a proclamação sem disfarces de atos psíquicos reais (...) Contudo, no rigor desta revolta, as obras recaem na simples coisalidade, como se se tratasse de castigar sua hybris em ser mais do que arte" (idem, p.122). Como se recebesse um castigo prometéico, por ter desafiado os limites da linguagem, o Expressionismo é ainda mais aproximado do mundo das coisas. Esta tensão entre objeto e "Arte", entre espírito e corpo, a angústia potencializada pela cisão irreconciliável, ao mesmo tempo que o anseio de uma comunhão dionisíaca dos opostos, são a tônica espiritual do Expressionismo, muito embora, formalmente, elementos simbolistas, art noveau e cubistas sejam reelaborados a partir desta visão de mundo. Senda "perigosa", no entender de Adorno, mas aberta e trilhada à exaustão pelas artes posteriores às vanguardas que levam ao extremo a sublimação da "arte" em atitude artística, e não em objeto, obra, artesania.

Mas, voltemos ao Expressionismo. A característica sublime da arte dita expressionista não é meramente iconográfica, não está na escolha de um "gênero", muito embora seja própria aos artistas do período a recorrência temática a alguns lugares-comuns da modernidade: a prostituta como metáfora ambígua do amor e da decadência; a cidade monstro. O expressionista quer enfatizar o caráter construído, a pincelada, o traço da representação e, neles, o acontecimento, a transcendência. Uma idéia de arte que cinde o "esquema de atividade" da mecânica artística e conteúdo para ten-

12 Por exemplo, no final do § 43 da Crítica do Juízo. Kant, “Da arte em geral” (Kant, 1980, p.244). 
tar refundi-los. Como leitores de Nietzsche, críticos de Kant, esses artistas procurarão ainda ser críticos da crítica romântica à representação. Grupos como Die Brücke ou Der Blaue Reiter procurarão outras "pontes" para superar (em suas manifestações mais radicais, sem mascará-los) as dicotomias, os dualismos. Mas essa já é outra história...

RUFINONI, Priscila Rossinetti. Mimesis of sublime: the Romantism and Expressionism reception of Kant. Trans/Form/Ação, (São Paulo), v.30(1), 2007, p.115-126.

- ABSTRACT: Starting from the analysis of the Kantian criticism, this text investigates the romantic and the modern conceptions of sublime and imagination. On the one hand, the romantic conceptions of sublime inaugurate the modern world. On the other hand, the expressionist conceptions show the confines of this world. The Critique of Judgment is the very locus where such distinctions can be drawn with precision.

- KEYWORDS: sublime, Kant, romanticism, expressionism, mimese.

\section{Referências biográficas}

ADORNO, Theodor W. Teoria Estética. Lisboa: Edições 70, s.d.

ADORNO, Theodor W. \& HORKHEIMER, Max. Dialética do Esclarecimento. Rio de Janeiro: Zahar, 1985.

ALBERTI, L. Da Pintura. Campinas:Unicamp, 1992.

ARENDT, Hannah. Lições sobre a filosofia política de Kant. Rio de Janeiro: Relume Dumará, 1993.

BENJAMIN, Walter. "Parque Central". In: Obras escolhidas III. São Paulo: Brasiliense, 1991.

BOZAL, Valeriano. Goya y el gusto moderno. Madrid: Aliança Forma, 1994.

BURKE, Edmund. Uma Investigação Filosófica sobre a Origem de Nossas Idéias do Sublime e do Belo. Campinas: Papirus, 1993.

HABERMAS, Jürgen. O Discurso Filosófico da Modernidade. São Paulo: Martins Fontes, 2000.

KANT, Immanuel. "Introdução à Crítica do Juízo". In: Kant II. 2. ed. São Paulo: Abril Cultural, 1980. (Col. Os Pensadores).

Crítica da Faculdade do Juízo. Lisboa: Imprensa Nacional/Casa da Moeda, 1992.

LYOTARD, Jean-François. Lições sobre a Analítica do Sublime. Campinas: Papirus, 1993.

NIETZSCHE, Friedrich. Ecce Homo. In: Obras Incompletas. 2. ed. São Paulo: Abril Cultural, 1974. (Col. Os Pensadores). 
POUSSIN, Nicolas. Lettres et propos sur l'art. Paris: Hermann, 1964.

RUFINONI, p.R. A morte de guarda-chuva: o sublime e o grotesco na obra de Oswaldo Goeldi. Dissertação de Mestrado em História da Arte, USP.São Paulo, 2000.

SCHELLING, Friedrich von. "A Divina Comédia e a Filosofia". In: Obras Escolhidas, 5. ed., São Paulo: Nova Cultural, 1991. (Col. Os Pensadores).

SCHILLER, Friedrich von. A Educação Estética do Homem. São Paulo: Iluminuras, 1989. 